\title{
Moving Forward and Making an Impact in Service Research: From Research Priorities to Research Methodologies
}

Bart Larivière and Jay Kandampully

The service discipline has a longstanding tradition and strong reputation for its impact on the marketing and management field in a meaningful way, which is both characterized and strengthened by its interdisciplinary nature.

Visionary scholars have acknowledged the crucial role of services that have gone above and beyond 'goods' dominance, and have conquered both the academic and business world by introducing and being the conceptual founders of the following themes: service quality, service value, servicescape, the role of employees and a service climate, service-profit chain, servitization, and return on quality. These topics have not only inspired other academics, but also managers and practitioners worldwide who realized that the pathway to customer centricity and success is through service. Indeed, one of the core characteristics of service research is to solve problems in which managerial relevance and academic rigor are intertwined.

The Marketing Science Institute (MSI) priorities, which have been identified and formulated from the responses of a sample of practitioners and scholars, are a testament to the fact that managerial relevant topics with a clear service touch are on top of the managerial agenda. At the same time, academic schools are also increasingly realizing that a marketing department that solely exists out of $\mathrm{CB}$ (consumer behavior) and modelers are not sufficient. Strategy/service-oriented faculties can form the necessary lifeblood to complement and bridge these two worlds. 
The service discipline, however, did not only successfully kick-start decades ago, it has continued to impact and grow and is currently flourishing as never before. According to Darwin's Evolution Theory, “It's not the strongest that will survive, but the one most adaptable to change". This also holds true for management that deals with continuous changes in the world in which customers are being served. Service researchers are in a privileged position, and even have the responsibility to undertake a significant role in this regard. And yes, we can, we did, and continue doing research in the following areas: servicedominant logic, co-creation, customer engagement, customer experience, service design, service delivery networks and ecosystems, customer participation in service organizations, collaborative service and the sharing economy, organizational frontlines, technology including artificial intelligence and robotics, transformative service research and societal impact, ... which are all rooted in service research and associated with brilliant service scholars from our SERVSIG community.

The service research priorities efforts by Ostrom and her colleagues $(2010,2015)$ have played an important role and had a crucial impact on the service field by helping to identify relevant, upcoming research ideas that deserve our attention and research time. These research priorities papers, as well as many other pre-conference, networking and thoughtleader events which have all contributed to acknowledge and stimulate relevant service research.

The goal of this special issue is to go one step further, by moving from research priorities to research methodologies that are relevant for service research. In doing so, we hope to inspire, as well as guide researchers, reviewers and editors. In particular, we need to focus on a set of methodologies that we believe can be highly relevant for future research endeavors. Indeed, the success and ingredients of a good and published research does not stop with a good 
idea/priority that is embedded in a strong conceptual foundation while having managerial implications. These ideas need to be blended with actual data and to be analyzed correctly (i.e., using an appropriate methodology). In addition, different methodologies are linked to specific types of research questions and data specificities. Specifically, knowing and being familiar with different research methodologies and their specific requirements, as well as providing the best examples of service research questions that can be addressed using these techniques, will not only be helpful in knowing the methodological underpinnings upfront, but it will also inspire other researchers to help to identify important service research topics.

In this special issue, we don't claim, nor intend to cover all the possible research methodologies that are relevant to service researchers, but rather to place research methodologies on the radar of researchers who are digging into research priority topics. Many methodologies are linked to analyzing survey data (e.g., construct and measurement validity, regression and SEM), experimental data (e.g., analysis of variance), past quantitative research findings (meta-analysis), ... are well-known, and well-applied in our discipline, and many examples exist about how to do it, and how to report it. So, there is no great need to focus on them. Instead, this special issue is designed to enhance our understanding of other methodologies that may be less known, through the publication of six papers. In their paper entitled "Bridging the Data-Divide between Practitioners and Academics: Approaches to Collaborating Better to Leverage Each Other's Resources”, Benoit and colleagues (2019) have focused on data, that is (will be, and should be) available to be analyzed, but has not been well exploited by researchers. They outline how to better make use of companies' data. Based on the literature, reflections from leading service research centers, and their own experiences, they develop recommendations about how to better collaborate in research and to engage with practitioners. 
In her paper entitled "Designing, writing-up and reviewing case study research: an equifinality perspective", Verleye (2019) introduces us to the wealthy spectrum of qualitative research, thereby providing concrete guidelines, as well as both existing and future research topics that could be addressed using the proposed methodologies.

In their paper entitled “Advancing Service Design Research with Design Science Research", Teixeira and colleagues (2019) underline the viable opportunity to contribute to the service discipline by creating the world, instead of just analyzing it, thereby introducing design science research (DSR) - which is adopted from Information Systems - as an appropriate methodological tool. Specifically, the authors use a service research example to showcase how DSR can help service design researchers to better ground their contributions based on existing knowledge, and to more robustly evaluate the suitability of these contributions to address future service design challenges.

In their paper entitled "From Words to Pixels: Text and Image Mining Methods for Service Research", Villaroel Ordenes and Zhang (2019), encourage us to consider new types of text and image data that are becoming more and more accessible to researchers - including methodological tools - but as yet have not been explored to their fullest potential. In doing so, they provide methodological guidelines and potential avenues for service research. In their paper entitled "Neuroscience in service research: An overview and discussion of its possibilities", Verhulst and colleagues (2019) introduce us to the world of neuroscience and its opportunities for service research. Specifically, they provide an overview of the existing neuroscientific tools and how service researchers might benefit from using them by focusing on both their challenges and strengths.

Finally, in her paper entitled "An update on customer value: state of the art, revised typology, and research agenda", Leroi-Werelds (2019) organizes, reviews, and extends the research on consumer value, which is core to both marketing (cf. the AMA definition of marketing) and 
the service discipline (as embedded in the service-dominant logic), and thereby focusing on how value can be conceptualized, measured and analyzed.

In summary, these articles not only enable the reader to become more familiar with the methodological underpinnings of several lesser known techniques, but also provide examples of past service research that have successfully applied these methods. In addition, these articles 'futurize' the potential usage of these techniques by proving some excellent examples of research ideas in light of the challenges associated with the future of service research. In doing so, the underlying goal of these examples are more for illustrative purposes, and hence do not cover the rich spectrum of research topics that have been identified by different calls for research as well as research priority articles.

Like service research priorities, research methodologies are never exhausted, and will need to be continually enriched and updated. As the world we are living in is constantly changing, as well as the need for current data, which includes both the methodological tools and software packages, our challenge will be to understand both the methodological opportunities and needs of the service research community. With the initiation of this research methodologies series, we hope to move this field forward, above and beyond research priority topics. Enjoy reading!

\section{References:}

Benoit (née Moeller), Klose, S., Wirtz, J, Andreassen, T.W., \& Keiningham, T.L. (2019). Bridging the Data-Divide between Practitioners and Academics: Approaches to Collaborating Better to Leverage Each Other's Resources. Journal of Service Management, 30 (6), XX -XX.

Leroi-Werelds, S. (2019). An update on customer value: state of the art, revised typology, and research agenda. Journal of Service Management, 30 (6), XX -XX.

Ostrom, A. L., Bitner, M. J., Brown, S. W., Burkhard, K. A., Goul, M., Smith-Daniels, V., Demirkan, H. \& Rabinovich, E. (2010). Moving forward and making a difference: research priorities for the 
science of service. Journal of Service Research, 13(1), 4-36.

Ostrom, A. L., Parasuraman, A., Bowen, D. E., Patricio, L., \& Voss, C. A. (2015). Service research priorities in a rapidly changing context. Journal of Service Research, 18(2), 127-159.

Teixeira, J.G., Patricio, L. \& Tuunanen, T. (2019). Advancing Service Design Research with Design Science Research. Journal of Service Management, 30 (6), XX -XX.

Verhulst, N., De Keyser, A., Gustafsson, A., Shams, P., \& Van Vaerenbergh, Y. (2019). Neuroscience in service research: An overview and discussion of its possibilities. Journal of Service Management, $30(6), \mathrm{XX}-\mathrm{XX}$.

Verleye, K. (2019). Designing, writing-up and reviewing case study research: an equifinality perspective. Journal of Service Management, 30 (6), XX -XX.

Villaroel Ordenes, F. \& Zhang, S. (2019). From Words to Pixels: Text and Image Mining Methods for Service Research. Journal of Service Management, 30 (6), XX -XX. 